\title{
Attribution of Community Emergency Volunteer Behaviour During the COVID-19 Pandemic: A Study of Community Residents in Shanghai, China
}

\author{
Tian Lai ${ }^{1}$ (D) Weiquan Wang ${ }^{1}$
}

Accepted: 9 December 2021/Published online: 10 January 2022

(c) International Society for Third-Sector Research 2021

\begin{abstract}
Based on grounded theory, the present study summarizes the transcripts from 32 in-depth interviews with Chinese community emergency volunteers to uncover the attributions of community emergency volunteering in China during the COVID-19 pandemic. Community emergency volunteering in China is affected by four main factors: inner awareness, the external environment, national policy, and publicity and advocacy. Among these factors, inner awareness and the external environment are the internal and social psychological attributions, respectively, of emergency volunteering. In addition, publicity and advocacy also play a role in both inner awareness and the external environment and, together with national policies, act on community emergency volunteering. Finally, the high level of trust of some volunteers in their ruling party and government is a deep-seated driving force of their volunteering, a factor that has not been emphasized in past studies.
\end{abstract}

Keywords COVID-19 - Emergency volunteering · Attribution research · Grounded theory

Tian Lai

2104462208@qq.com

1 School of Political Science and Public Administration, East China University of Political Science and Law, Room 1102, No. 46, Lane 128, Kongjiang Road, Yangpu District, Shanghai, China

\section{Introduction}

In the early nineteenth century, the earliest volunteer services were instituted through religious bodies in Western countries, where people took the initiative to contribute their time and energy to society based on their own beliefs, morals, and conscience. Volunteering services usually involve the donation of one's talent, time, and energy to others or organizations without compensation (Gibelman \& Sweifach, 2008) and comprise long-term, planned, prosocial behaviours that benefit strangers and usually occur in an organizational setting (Penner, 2002). During the COVID-19 pandemic in 2020, as a grassroots response to the public health emergency, community emergency volunteers and the emergency volunteer services, they provided played a significant role in pandemic prevention and control. For example, emergency responder communities (ERCs) can make full use of the resources and professional expertise of emergency volunteers in all areas of service delivery to affected people, thereby reducing economic and human losses (Alzaghal \& Momani, 2017).

The essence of community emergency volunteer activities is community volunteer service under "abnormal" scenarios, which is a special form of volunteer service in the face of public emergencies. Unlike traditional voluntary work that pursues independence, during the COVID19 epidemic, citizen emergency volunteers are more urgently required to cooperate with civil society (including community groups) and local governments to protect public health. Emergency volunteering during COVID-19 is different from other disaster relief volunteer services. For example, in China, emergency volunteer services during the epidemic present a situation where multiple parties' joint productions are dominated by the national level (Miao et al., 2021). In addition, during this period, the value 
motivation of volunteers to provide services decreased, while the degree of moral motivation based on altruism and service to the community and the people increased (Domaradzki \& Walkowiak, 2021). These changes occurred because the COVID-19 epidemic is an unprecedented, global, and far-reaching public health crisis, which poses an immense challenge to the emergency management of governments in China and the West. In terms of extension, community emergency volunteers, compared to volunteers under normal conditions, have a more prominent role when facing major crises at the grassroots level as a reserve force to supplement frontline rescuers. As a result, emergency volunteer groups tend to be younger and less educated than volunteers under normal conditions. However, community emergency volunteers can often provide additional emergency response capabilities to deal with more frequent emergencies and disasters in the future (Rotolo \& Berg, 2011). Of course, unlike volunteers under normal circumstances, emergency volunteer services also have shortcomings such as the size, availability, and commitment of the labour force (Mayorga et al., 2017).

After the SARS epidemic in 2003, China began to build an emergency management system and in recent years has also sought the development of grassroots emergency volunteer service organizations. However, due to the enormous differences between the politics and culture of Western countries and China, they also behave differently in the emergency volunteer process. From a political perspective, voluntary activities organized by the government from top to bottom are very common in China. The Chinese government plays an important political role in the risk management system including resource guarantees, technical support, and disaster risk management, and it assumes the mission of communicating and cooperating with grassroots voluntary organizations and other nongovernmental organizations (Shi, 2012). For a long time, China has also presented a voluntary service system of joint production led by the state (Miao et al., 2021). Its grassroots emergency voluntary services have been incorporated into the country's ruling planning system to strengthen the country's ideology, innovate social management, maintain social stability, and maintain the needs of the Communist Party of China (CPC) for long-term governance (Hu, 2020). In addition, citizen networks, institutional trust, party membership, and types of work units are closely related to the voluntary services of government organizations (Wu et al., 2018). For example, in Shanghai, a coexistence of non-governmental emergency volunteer service organizations and normal volunteers in the system has been initially formed (Monllor et al., 2020).

At the same time, cultural experience is the key to communication planning in crisis situations (Harro-Loit et al., 2012). There is a certain connection between social cultural background and disaster risk measurement standards, so emergency managers can explore the impact of cultural factors on voluntary services such as disaster relief and formulate emergency voluntary service policies based on this (Kasdan, 2016). For example, the Chinese government has shaped the values of emergency volunteer service through disaster reduction education, emergency culture, and cultivating related skills (Luova, 2011). In the West, voluntary service is promoted in a free and democratic manner, which can be explained by variables such as education, religion, and social capital (Liu \& Zhang, 2020). Volunteer service is more effected at the personal level (Hustinx et al., 2010). In most developed countries, cultural factors are considered one of the main obstacles for civil volunteers to participate in disaster relief (Whittaker et al., 2015). The Western context believes that voluntary service and health culture may be positively correlated, but this is rarely explored in non-Western countries represented by mainland China (Wu \& Bies, 2020).

In summary, there are many differences between emergency volunteer behaviour and normal volunteer behaviour, and emergency volunteer activities during COVID-19 are also different from other disaster relief volunteer activities. In addition, when facing emergency voluntary affairs, Chinese and Western countries also have differences in politics and culture. For Western countries, existing studies have paid less attention to the differences in this type of emergency volunteer work, and Western scholars have often ignored the "power of the ruling party and government" in the current epidemic to China's grassroots emergency volunteers. For China, there is currently no systematic and scientific qualitative research on the group of community emergency volunteers in the Chinese academic circle; there is especially a lack of attribution research on the participation behaviour of this group. There is thus the possibility of cutting-in for the research of this article.

In this context, the present study uses grounded theory as a guide and in-depth interviews as an approach to investigate emergency volunteers in Chinese communities and to explore the factors that influence this group's emergency volunteering as well as the underlying mechanisms: what are the internal and external factors behind this behaviour? The mechanism by which the relevant factors influence the behaviour of volunteers themselves is also elucidated to fill gaps in the literature.

\section{Literature Review}

Scholars in various countries have reported informative research results related to volunteers' behaviour, focussing on factors that affect volunteers' positive/negative attitude 
towards volunteering. In this regard, scholars generally agree that the sustainability of volunteer services is influenced by motivation to participate ( $\mathrm{Ng}$ et al., 2019), which is summarized in this paper as internal and external factors.

First, there are internal factors that influence volunteering. A related study in China, Germany, Turkey, and the USA confirmed that in different cultures, continuous voluntary service is related to explicit prosocial motivations, and when the implicit prosocial motivations are also high, the explicit prosocial motivations. There is a strong relationship between social motivation and continuous voluntary service (Aydinli et al., 2015). Compared with other social groups, student volunteers are more influenced by internal altruistic motives rather than external motives (Mekonen \& Adarkwah, 2021). It has been suggested that from the perspective of self, one's motivation to help others is positively related to volunteering, while motives of self-enhancement are negatively correlated with volunteering (Mowen \& Sujan, 2005). Additionally, expectations of self-identity and perceptions are the strongest predictors of volunteer time and service delivery (Finkelstein et al., 2005). From a psychological contract perspective, Kragt et al. (2018) divided volunteers into three types ("focused", "lost" and "overenthusiastic") and pointed out that having too many or too few expectations leads to a low intent to volunteer. Based on the ultimate goal of volunteering, the motivations for volunteering can be roughly classified into four categories, i.e. egoism, altruism, collectivism, and principlism (Batson et al., 2002). Some scholars have also investigated the antecedents of volunteers' behaviour within a hierarchical model of "motivation and personality", concluding that "functional motives act like reasons for acting" (Mowen \& Sujan, 2005). In addition, the intrinsic motivations for volunteering also include "expressing personal values", "understanding one's environment", and "interacting with like-minded people" (Nanavaty, 2020). Caricati et al. (2020) showed that volunteers' professional identification is negatively related to burnout but positively associated with compassion satisfaction, with both effects mediated by self-efficacy; furthermore, they examined in detail the effects of volunteers' self-efficacy and identification on the positive and negative aspects of volunteers' professional quality of life.

In addition, internal factors such as age, gender, family, employment status, and neighbour relations may also cause differences in related voluntary services, as reflected by the differences in motivational factors for volunteering among different age groups. Specifically, young volunteers tend to be motivated by and obtain outcomes related to interpersonal relationships, and the prosocial attitudes of middleaged volunteers have a strong influence on their participation behaviour (Janoski et al., 1998), while older volunteers have a propensity to be motivated by community obligations (Omoto et al., 2000). Kulik (2016) argued that "motives of social solidarity and of escape from reality through volunteering are higher among volunteers in late adolescence than among volunteers in middle and late adulthood". Among volunteers of all ages, the most influential variables are parental volunteering and parental education level, reflecting the power of role modelling (Dury et al., 2016). In terms of gender, women are more likely to engage in formal volunteering and informal care than are men (Wang et al., 2016), reflecting that women are more driven by a motivation to volunteer. It has been shown that although more Chinese women have escaped the confines of the family, their social participation outside the family is still bound by the family (Sheng \& Weirong, 2020). This situation still occurs because volunteer emergency services adversely impact the families of female volunteers, resulting in hardship for their families (Cowlishaw et al., 2011). The quality of life indicators also includes community awareness, efficacy beliefs, and participation strategies of emergency rescuers (Cicognani et al., 2009). In addition, a logistic regression analysis showed that individual employment status and relationships with neighbours are closely related to the continued participation of volunteers (Nemoto et al., 2018). People who can receive more support from neighbourhood organizations can perceive a higher level of social cohesion and less mental stress (Miao et al., 2020). From a professional perspective, unlike other types of volunteers, medical students spend longer and more days engaged in emergency volunteer services (Bazan et al., 2021). They are more likely to be motivated by a sense of purpose or responsibility, altruism, and professional values (Tempski et al., 2021). For example, veterans are more likely to volunteer for political groups and civic organizations than are nonveterans (Nesbit, 2017).

External factors also influence volunteering. In terms of external influences, the status of emergency planning and training and education at the grassroots level will have an impact on emergency volunteer activities (Kim \& Jung, 2016). In terms of external influences, support and recognition as well as perceptions of experience have positive impacts on the continued willingness to volunteer, while career has a negative impact (Oh, 2017). In addition, the interaction with others and the cultural services enjoyed from the external ecosystem will affect the frequency of people's participation (Takase et al., 2019). The positive attitude represented by volunteerism and the positive signalling effect exhibited by the outside world may have enhanced the rate of people's participation in volunteering during this pandemic. A study has demonstrated that the rate of volunteering is significantly higher in countries with a positive signalling effect of volunteering (Handy et al., 
2009). In a study on the influence of a programme regarding community emergency teams (CETs), Billig (2019) noted that regardless of success, "the positive reinforcements received ... from the adult participants' feedback and the responses of the surrounding community elicited strong feelings among youth and adults". Chinese scholars echoed that continuous engagement of emergency volunteers in related matters is influenced by social network factors (Luo \& Wang, 2012). In contrast, inappropriate external policies, poor management of volunteer organizations (Shi et al., 2018), and underlying social inequalities (Southby et al., 2019) are all major obstacles for volunteers to translate their willingness to participate into actual action. Milbourn et al. (2018) conducted a survey of 64 volunteers who formerly participated in but later quit from an international volunteer organization, and their results showed that "work overload and burnout", "lack of autonomy and voice", "alienation and cliques", "disconnect between volunteer and organization" and "lack of faith in leadership" all contributed to the attrition of volunteers. Therefore, managers of volunteer emergency services should carefully examine the motivation of volunteers and provide targeted guidance so as to better retain existing volunteers and recruit new ones into the organization (Bruyere \& Rappe, 2007).

As seen throughout the above literature, the factors pertaining to the participation behaviour of volunteers are mainly studied from the internal and external perspectives, and follow-up issues related to volunteering are gradually being valued by researchers (Wilson, 2012). Nevertheless, the following gaps still need to be filled. (1) There is still relatively scarce research on the specific subject of community emergency volunteers, the topic investigated in this study. Most of the existing research subjects are volunteers in normal situations, the intension and extension of whom are not completely consistent with the subjects in the present study. As a result, past research variables and related findings can only serve as a reference for the present study. (2) Different scholars reached different, sometimes even completely opposite, conclusions on the influencing factors of volunteering. For example, Mowen and Sujan pointed out that "the motive of self-enhancement was negatively related to" volunteering behaviours, while Batson et al. (2002) and Nanavaty (2020) argued that egoism exists and hence volunteerism can highlight "personal value" and allow one to "gain a sense of purpose". (3) Due to the differences in national conditions and systems between China and Western countries, there are also differences in who will solve public problems and promote general welfare at the level of emergency volunteer services (Boyte, 2005). Therefore, when investigating the influencing factors and related mechanisms of emergency volunteer behaviour in Chinese communities, the role of the ruling party and government in the grassroots emergency volunteer system should be fully considered. For example, what is the mechanism by which the appeals of the ruling party and the intervention policies implemented by relevant departments influence the behaviour of emergency volunteers in the community? What are the differences between China and the West in emergency volunteer work? Unfortunately, such issues have often been overlooked in previous studies. (4) From the perspective of the technical methods of the research, past research has seldom been carried out with exploratory qualitative research methods, and the ideas of grounded theory are rarely applied to the research of the special group of emergency volunteers, so this research has a methodological innovation.

To address this research gap, in-depth interviews and exploratory qualitative research were conducted to investigate the behavioural psychology and corresponding mechanism of action of China's community emergency volunteers as a special group in the context of the COVID19 pandemic.

\section{Research Methods and Interview Design}

The aim of this study is to investigate the attributions and related mechanisms of community emergency volunteering in China in the context of the COVID-19 pandemic. This research conducts qualitative research based on grounded theory and collects samples through in-depth semi-structured interviews, thereby warranting an exploratory study. Grounded theory was originally born out of a collaboration between sociologists Glaser and Strauss through their study of the death process in hospitals. The theory advocates "uncovering theories on the basis of data" rather than testing one's own hypotheses based on theories and conclusions already available in the literature. The grounded theory can be considered a top-down research method for substantive theory construction based on experience and data (Chen, 2000).

In general, the use of this theory for exploratory research requires three key steps-open coding, axial coding, and selective coding of the data (Strauss \& Corbin, 1990). In addition, this method adopts an inductive and iterative process requiring data collection and analysis as well as subsequent repetitive work and often involves inductive analysis and frequency comparisons of the resulting samples based on relevant requirements of qualitative research. A process of induction and deduction in which conjectures about data were formed based on the literature and further empirical exploration was used to verify these conjectures (Saunders et al., 2018).

In this context, the interview work of this research was carried out according to the following four steps: (1) In the 
early stage of the research, the researcher used Google, WEB OF SCIENCE, China HowNet, and other mainstream Internet resources to search for and read related documents. The researcher browsed and collected service cases, interview records, personal work diaries, and audio and video files of relevant news reports of representative Chinese and Western emergency volunteers during the COVID-19 pandemic to form an early understanding of the literature. After preliminary analysis, preliminary conjectures and inferences about the voluntary behaviour of the group of emergency volunteers were obtained, and possible theoretical interpretations of the data were made. (2) Second, based on the early theoretical explanations and conjectures, the director further deduced the subsequent research hypotheses. (3) Then, in the real world, in-depth interviews were used to further develop the aforementioned theories, which required prior selection of the sampling scope and sampling strategy (Robinson, 2014). Specifically, based on a semi-structured questionnaire prepared in advance, this study conducted in-depth interviews with Chinese volunteers who participated in community emergency volunteer services during the COVID-19 pandemic. Conducted through field interviews or by telephone, each type of interview followed the standard interview procedures of qualitative research, and interviewees were informed of the relevant topics in advance to reduce their bias in understanding the topics. On-site interviews were conducted one on one, and telephone interviews lasted for 30 to $60 \mathrm{~min}$ to ensure that the interviewees could speak freely. Starting from the scope of sampling, this study first identified the target group for interviews as "emergency volunteers," and then further narrowed the scope of theoretical sampling, taking Shanghai as the source of the sample from the regional level. Because there are many communities under the jurisdiction of Shanghai, the sampling scope was narrowed again, and finally, the communities in Shanghai were regarded as the basic unit of the sampling of this study, and an attempt was made to "the person most likely to bring rich information to the research topic" in this area. Semi-structured in-depth interviews were conducted. This research used stratified sampling. That is, the interviewed volunteers were subdivided into multiple sub-groups (called strata) according to their gender, age group, community and other characteristics, and then, stratified sampling was performed on these subgroups. Interviewees were asked about their internal and external motivations for participating in emergency volunteer work in the community during the COVID-19 pandemic, as well as their actual feelings about volunteer activities. They also gleaned the interviewee's evaluation of other volunteers and companions around them. We used inner psychology to ensure the objectivity of the answer. Examples of interview questions are as follows: 1. During the new crown epidemic, how do you view the role of community emergency volunteers? 2 . What do you think is the reason why everyone took the risk of being infected, became emergency volunteers in the community, and devoted themselves to the fight against the epidemic? 3. What do you think of the volunteers around you and how is your cooperation? 4. In the process of community emergency volunteer service, what makes you satisfied (happy) or dissatisfied (unhappy)? 5. In your opinion, what are the factors that hinder people from participating in community emergency volunteer activities during this new crown epidemic? 6. In your opinion, how can we promote community residents to participate more actively in community emergency volunteer activities? (4) Finally, the interview process was recorded or recorded with the consent of the interviewee and then converted into text, which was sorted out to form a memorandum of this research. It is worth mentioning that although the outline of the interview was determined ahead of time, it was adjusted according to the actual situation in the process of communicating with the interviewees. In-depth questions were asked around the outline and related concepts and categories for deeper insights and detailed information.

\section{Reliability and Validity}

This research follows the principle of "theoretical saturation" pursued by grounded theory in the sampling process; that is, the generic attributes were formed through sampling until no new attributes and themes appeared. Theoretical sampling is one of the core procedures of grounded theoretical methods. Unlike quantitative research methods, theoretical sampling does not excessively pursue the demographic representativeness of the sample, and there is no clear regulation on the sample size, but it focusses on developing theories and concepts. In consideration of the scientificity and objectivity of the interview results, this research focusses on the balance of sample distribution in the selection of interviewees in the early period and the process of combing the interview records in the later period. The selected interview samples included various communities in Shanghai at the spatial level and emergency volunteers of different age groups, genders, occupations, and political identities at the personnel structure level, so the sample quality is good. Representativeness and objectivity and the overall distribution of the samples obtained are also relatively balanced.

On the other hand, in the follow-up text coding link, this research also pays attention to reliability and validity. Specifically, the coding of the interviews was initially conducted by a researcher, and the coding results were modified and adjusted after verification by two or more experts in the consulting research field. Finally, the coding 
experience was shared through collaborative discussions, and the suggestions of many authoritative experts are used in these free discussions to form an exploratory research coding. In the process, the researchers adopted a strict attitude towards the continuous comparative analysis of the data obtained; therefore, the coding classification has been substantially improved, and new concepts and categories have been continuously discovered, which has also deepened to a certain extent. To explore the theoretical basis of the attribution of community emergency volunteer activities, this research has more theoretical value.

\section{Survey Results and Coding Analysis}

A total of 39 respondents were interviewed in this study, including 18 men and 21 women. Among them, four interviewees refused to accept the interview due to heavy work, time inconvenience, and other reasons. Therefore, this study ultimately obtained 35 samples of valid interviews, and the overall response rate of interviewees was approximately $89.74 \%$. After sorting and summarizing the 35 effective interview samples, it was found that the study reached theoretical saturation when the interview records of 32 interviewees were coded and summarized. To further verify, the researcher performed the same coding analysis on the remaining interview texts and found that there were indeed no new concept categories, which improves the scientificity and reliability of the research results in this paper and makes the research conclusions feasible. In terms of age distribution, overall, the interviewed Chinese community emergency volunteers were predominantly middleaged and over 55 years of age (accounting for approximately $78 \%$ of the total interview sample); most were public-spirited citizens with abundant free time, and some of them were members of the Communist Party of China (hereinafter referred to as the Party). These characteristics are generally consistent with those for community volunteers in China, representing homogeneous elements of the volunteers in China's grassroots communities during this pandemic.

Open coding requires a full range of coding of the collected data, and any statement or paragraph that can be identified and coded in the data should be coded and conceptualized. Using NVIVO qualitative analysis software, a line-by-line coding approach was used in the present study to analyse and code the original interview data word by word. In addition, to restore, as much as possible, the original intension of the respondents, the "original native language" of the respondents was used as the initial label to uncover the concepts. However, because the concepts formed were at a low level and some concepts had some degree of crossover, it was necessary to refine and summarize them in-depth and form categorized, systematic concepts. For categorization, the initial concepts with less occurrence frequency (fewer than three times) were eliminated, and only those occurring more than three times were retained. Based on the results of open coding, 15 initial concepts were generated: sense of individual responsibility, role model image, team climate, perception of individual efficacy, sense of community, infrastructure support, social morality, moral incentive, material incentive, leadership of the Party and government, self-enhancement, advocacy of the Party and government, care of the Party and government, administrative regulations and related policies, and publicity and communication.

As the second stage of coding, the conceptual codes are further classified through the fusion of inductive and deductive thinking, and hence, new categories can be obtained by inductively integrating the fragmented categories, from which the corresponding logical connections between categories can be constructed. It was found that there were indeed different degrees of connection between different categories, with certain hierarchies and inclusion relationships. In this context, after scrutinizing and summarizing them once again, a total of 11 related categories were obtained: sense of individual responsibility, perception of individual efficacy, self-enhancement, role model image, motivation of team members, overall social morality, infrastructure support, moral and material incentives, administrative regulations and policies, government publicity and advocacy, and non-government publicity and advocacy.

After the above two rounds of coding, connections between categories gradually emerge, allowing more deep mining using selective coding, so as to extract "core categories". After that, the connections between the core categories and many other categories can be analysed, and a "story line" can be developed to describe the overall behaviour. Through selective coding, this study ultimately identified six linking mechanisms (Table 1), which will be elaborated in the following discussion, where oral statements by representative respondents will be quoted.

\section{Linking Mechanism 1: Effect of Inner Awareness on Community Emergency Volunteering}

Based on coding, an individual's inner awareness is an internal psychological factor of community emergency volunteering. This kind of inner consciousness is manifested as an emotional identification with political parties and communities and externalized as its own actions (Beyerlein \& Sikkink, 2008). As expressed by a community emergency volunteer interviewed in the present study: 
Table 1 Selective coding and typical linking mechanisms

\begin{tabular}{|c|c|}
\hline Linking mechanism & Intension \\
\hline $\begin{array}{l}\text { Inner awareness } \rightarrow \text { Community emergency } \\
\text { volunteering }\end{array}$ & $\begin{array}{l}\text { During the epidemic, psychological factors, such as the sense of individual responsibility, } \\
\text { perception of individual efficacy, and inner self-enhancement, are the psychological } \\
\text { attributions that motivate individuals to engage in community emergency volunteering in China }\end{array}$ \\
\hline $\begin{array}{l}\text { The external environment } \rightarrow \text { Community } \\
\text { emergency volunteering }\end{array}$ & $\begin{array}{l}\text { During the epidemic, factors in the external environment, such as role model image, motivation } \\
\text { of team members, and overall social morality, all constitute important attributions of } \\
\text { community volunteering in China, thus bringing the behaviour of individual volunteers in line } \\
\text { with social norms and values }\end{array}$ \\
\hline $\begin{array}{l}\text { National policies } \rightarrow \text { Community emergency } \\
\text { volunteering }\end{array}$ & $\begin{array}{l}\text { During the epidemic, whether the Chinese government provides community emergency } \\
\text { volunteers with adequate infrastructure facilities, whether material and moral incentives are in } \\
\text { place, and whether relevant administrative regulations and policies are perfected and } \\
\text { implemented all affect the cost-benefit of emergency volunteering and are related to the } \\
\text { enthusiasm of volunteers' action, thus playing a role in emergency volunteering }\end{array}$ \\
\hline $\begin{array}{l}\text { Publicity and advocacy } \rightarrow \text { Community } \\
\text { emergency volunteering }\end{array}$ & $\begin{array}{l}\text { During the epidemic, relevant departments publicly recognize emergency volunteers in Chinese } \\
\text { communities and their deeds through various media and channels using different publicity } \\
\text { methods, frequencies, and coverage and communicate with non-volunteers, thus influencing } \\
\text { emergency volunteering }\end{array}$ \\
\hline $\begin{array}{l}\text { Publicity and advocacy } \rightarrow \text { The external } \\
\text { environment }\end{array}$ & $\begin{array}{l}\text { During the epidemic, relevant departments publicly recognize emergency volunteers in Chinese } \\
\text { communities and their deeds through various media and channels, so as to influence the } \\
\text { external environment, such as drive the social climate and shape the role model image, thus } \\
\text { playing a role in emergency volunteering }\end{array}$ \\
\hline Publicity and advocacy $\rightarrow$ Inner awareness & $\begin{array}{l}\text { During the epidemic, relevant departments publicly recognize emergency volunteers in Chinese } \\
\text { communities and their deeds through various media and channels, so as to influence individual } \\
\text { inner awareness. This action can clarify misunderstandings, reduce panic and shape the } \\
\text { cognitive well-being of individuals, thus playing a role in emergency volunteering }\end{array}$ \\
\hline
\end{tabular}

The spirit of volunteers, I think, is a strong sense of responsibility and ownership. So, I can also assist the Party and government departments within my capacity, such as helping to measure body temperature and issue access passes.

Previous research has suggested that a volunteer's behavioural motivation is positively associated with his/her self-concept, prosocial personality, volunteer time, and motive strength, while extrinsic orientation is closely related to external motives (especially career aspirations) (Finkelstien, 2009), thereby confirming the interview data in the present study:

We should let people see the benefits of participating in community volunteering for themselves and for social development. In this way, people will feel that they are benefiting from it, and more people will sign up for it.

On the one hand, many respondents expressed that their "comprehensive [abilities have] been improved" through volunteering, reflecting the association between the intrinsic motivation of volunteering and the concept of selfenhancement. On the other hand, the statement of "to be able to serve my clients better in the future" also reflects the relationship between volunteerism and career aspirations. This sentiment is precisely echoed by Ohmer, who argues that volunteers who participate in the everyday activities and decision making of volunteer organizations increase their self-efficacy, organizational collective efficacy, and sense of community (Ohmer, 2007).

In addition, the present study on the behavioural attributions of community emergency volunteers in China during the COVID-19 pandemic found that the most prominent characteristic of emergency volunteers is that as advanced members of the community, they tend to have high ideological awareness and a sense of moral responsibility; that is, their own sense of responsibility and efficacy promotes their commitment to volunteering in grassroots communities. This characteristic can be reflected in the statements of most of the respondents, such as "I think this is a sense of responsibility", "we all have a responsibility to fight the pandemic and protect our homes", and "community volunteers play a very important role".

However, the sense of responsibility and efficacy does not necessarily lead to actual volunteering behaviour; in other words, awareness and behaviour are not fully aligned (Aiken, 2008). This phenomenon is reflected by the common phenomenon of "high willingness but low participation rate" in China's grassroots communities (Xie, 2017). The reason for this phenomenon is suggested in the responses of the volunteers interviewed, e.g. "fear of 
infection" and "occupied with a busy work schedules and household chores". The following examples are provided:

I feel that a few people may have a great fear of COVID-19 and being infected, so they are afraid to volunteer.

I think the participants in community volunteering are mainly retired workers. This is because the working people are quite busy, and those who have just retired are facing [the difficulty in taking care of] their elderly parents and young children, while some others are not in good health and are afraid of getting infected if they go out.

\section{Linking Mechanism 2: Effect of the External Environment on Community Emergency Volunteering}

The external environment exerted an influence on an individual's volunteering behaviour through role modelling, team member motivation, and overall social appearance, thus promoting volunteering.

A previous study argued that social identity is first derived from the self-definition of the individual in a group (Vanbeselcaere, 1994). The degree of citizenship identity affects volunteers' participation behaviour (Liarakou et al., 2011). It is precisely because volunteers in the community perceive themselves as belonging to a particular social group that they accept and follow the code of conduct and norms of value of the group, thus making their position in the society clear through their "specific social identity (Deschamps \& Devos, 1998)". This situation is common in China's grassroots communities. On the one hand, the community emergency volunteers in China are inspired by the role models and benchmark figures during the pandemic, and they follow and learn from others as role models and benchmarks. On the other hand, under the influence of the external social environment, China's community emergency volunteers have also developed a sense of self-identity and expect to become role models themselves. For example,

I am a Party member, and it is my duty to contribute when the country needs it. Some retired seniors, who are grateful to society, also actively join the ranks of community volunteers and contribute to the extent possible.

Party membership here represents a political identity and means that the respondents themselves need to "always play an exemplary role"; in other words, membership implies the recognition and acceptance of a series of related rights, duties, and responsibilities (Faulks, 2000). This situation is rarely seen in the research on factors that influence volunteer behaviour in Western countries, but it has been quite common in Chinese grassroots communities during this pandemic, thereby well reflecting how the differences in national conditions and institutions between China and Western countries affect the behaviour of volunteers in respective countries. For example, some respondents also showed their respect for role models:

We are retired and have nothing to do at home. Then, isn't it good to do something for everyone? Medical workers went to the front line of the battle against the pandemic right after [Lunar] New Year's Eve. [Compared to them,] we did nothing worth mentioning for the community.

In addition, previous research has also shown that individuals tend to draw close to the values, norms, and standards of a referent, motivated by the desire to gain external approval and appreciation as well as to avoid external blame and discrimination.

The members of our [community emergency volunteer] team are all out working at the entrance of the community, rain or shine, and no one has ever complained of the hardship. Many of them are senior Party members, and there are also several veterans. Everyone kind of never gives a thought of personal gains or losses, which is also an incentive for me.

As Jasper pointed out, social mobilization should focus on the impact of positive emotions on people's participation in a movement so that the potential social forces can be fully mobilized (Jasper, 1998). The "cordial working relationship between each other" in Chinese volunteer teams fighting this pandemic is undoubtedly a positive emotional experience.

In addition, social networks and community culture increase the possibility of formal and informal volunteering, and considerations of community also contribute to the articulation of various forms of individual and collective action as well as broader civic and societal participation (Omoto \& Snyder, 2002). Most typically, respondents frequently mentioned "community as my home", "all for one and one for all" and other related expressions:

In the community, [we] should form some volunteer atmosphere, vigorously promote the patriotism, and inspire people's sense of ownership. [We] should advocate the spirit of "all for one and one for all" and work together to create a harmonious, stable community environment. 


\section{Linking Mechanism 3: Effect of National Policies on Community Emergency Volunteering}

A study has shown that well-defined public policies can promote volunteerism and encourage youth participation (Mainar et al., 2015). The state's allocation of infrastructure, both material and moral incentives, and the introduction and improvement of relevant administrative regulations can influence and guide individual behaviours. For example,

Our government has done a great job. In general, it can provide, in a timely manner, the hardware resources we need for volunteer activities. For instance, when we ran short of masks during the pandemic, the secretary of our neighbourhood committee delivered them to the volunteers in person.

For community emergency volunteers, the appropriate provision of basic material security, such as food and medicine, may provide more confidence and motivation for emergency volunteers to fight the pandemic. For example, the respondents often mentioned reasonable requests to relevant government departments, e.g. "offering meals while working" and "providing more personal protective equipment (PPE)". A study has also shown that incentive policy measures can have a profound effect on volunteers and that the introduction of such national policies not only affects volunteers' current behaviour but also leads to longlasting changes (Dawson et al., 2019). For example,

Rewards should be a combination of material and moral ones, dominated by moral rewards and supplemented by material rewards, which should be mainly in the form of PPE. I heard that in some areas, medical insurance was provided to volunteers to relieve their worries about being infected. I think this is a very good policy.

The use of symbolic rewards is also significant in explaining the variations in the satisfaction of volunteers, volunteer service hours per month, and length of service (Cnaan \& Cascio, 1999). For example,

Some of our volunteers have leg problems and really have a hard time standing guard for long, with leg numbness, back pain, and thirst. However, upon hearing a sincere 'thank you' from the residents, our volunteers feel so blessed as well as more responsible. I hope the government can publicize and reward outstanding community volunteers

\section{Linking Mechanism 4: Effect of Publicity and Advocacy on Community Emergency Volunteering}

The interview materials showed that publicity and advocacy have promoted community emergency volunteering in China and reflect the strong guidance of the Party and the government. This finding is grounded in the context of the COVID-19 pandemic and in line with China's national conditions and institutions. A study on collective action participation pointed out that when the membership structure remains unchanged, members who pay attention to the relevant organizational mass media are more effective in forming a consensus on goals than those who interact with other members (Collins-Jarvis, 1997). For example,

It is a must and no big deal for me to make some contribution under the publicity and leadership of the State. Hopefully, it is best for society and the government to promote and publicize the positive energy of volunteers so that more people can fulfil their responsibilities and obligations as a citizen.

In addition to government publicity, social media also play a role in civic engagement (Kaun \& Uldam, 2017). For example,

Yesterday, some of the fellow townsmen who came back to Guangzhou posted the news about our volunteer team giving out 'care packages' on WeChat Moments, so they came to get it as soon as they arrived, saying that 'Guangzhou people are so warmhearted. Thank you'.

This is also a good illustration of the positive link between discussions about the media and civic engagement (Erentaite et al., 2012). In China, media publicity and advocacy related to the pandemic mostly reflect the importance of community emergency volunteer work associated with relevant government departments and promote and encourage the development of grassroots emergency volunteering.

\section{Linking Mechanism 5: Effect of Publicity and Advocacy on Inner Awareness and the External Environment}

In the process of emergency volunteer service, we should try to establish contact with other citizens. Those who do this can achieve success. Otherwise, they may lose legitimacy and meaning and eventually fail (Edelenbos et al., 2016). Therefore, an important goal of grassroots organizations is to make emergency volunteers identify with voluntary service through various kinds of publicity so that their identity can benefit from social trust and social honour 
(Cheung et al., 2015). During the pandemic, relevant government departments played a role in both inner awareness and the external environment through various publicity channels and with different intensities of publicity and advocacy, as many respondents mentioned:

In my opinion, to promote people to participate more actively in community emergency volunteering, vigorous publicity by newspapers and media is required to have more publications and reports recognizing the exceptional deeds and personal charm of outstanding volunteers.

Its role in inner awareness is also reflected as follows:

I think it is understandable that everyone has some kind of fear about a new problem and a new thing [referring to the COVID-19 pandemic]. Therefore, it is still necessary for relevant government departments and media to do a good job in publicizing our community work and telling others what it is really like, so as to alleviate people's inner fears and promote overall volunteering.

In addition, from the perspective of the external social environment, the high intensity and timeliness of publicity and advocacy such as the "vigorous publicity of positive energy to society" were also frequently mentioned by the respondents, one of whom stated the following:

I think we can showcase good volunteering activities or something alike to people in the community, telling them that our [emergency volunteering] work is actually very meaningful.

\section{Discussion and Conclusion}

This study explored a multitude of influencing factors and the corresponding mechanisms behind volunteering by community emergency volunteers in China under the backdrop of the global COVID-19 pandemic. It is concluded that community emergency volunteering in China is affected by a combination of internal factors (inner awareness) and external factors (the external environment). In addition, the present study also finds that the intensity of publicity and advocacy also plays a role in both inner awareness and the external environment and, together with national policies, acts on community emergency volunteering.

Past research has noted that bottom-up volunteerism includes a strong desire for meaningful personal engagement that state-led volunteer programmes and organizations typically fail to provide (Spires, 2018). However, the development and growth of community emergency volunteering in China during this pandemic are based, in large part, on volunteers' trust in the CPC and the government, especially in the CPC members among the volunteers. While this is certainly a result of the characteristics of China's national conditions and institutions, it also fills a gap regarding the intervention power of the Party and government leadership, which has often been overlooked in previous studies on community emergency volunteerism. Therefore, the following conceptual framework is obtained (Fig. 1).

As shown in the figure, the four main categories (i.e. inner awareness, the external environment, publicity and advocacy, and national policies) are the main attributions of community emergency volunteering in China during the COVID-19 pandemic, and some volunteers' trust in the CPC and government is always present in their volunteering. In particular, inner awareness is an internal psychological factor, and the external environment is an external social factor; however, both are influenced by the publicity and advocacy of governmental departments and other media. According to the social learning theory, human behaviour is often influenced by both internal and external factors and is the result of the combined effect of the two (Myers, 2006). In other words, the volunteering behaviour of Chinese community emergency volunteers is the product of the interaction between inner awareness and the external environment. The theoretical model constructed in the present study is mainly based on in-depth interviews with a small sample of community emergency volunteers and the related qualitative research methods; therefore, its significance should be further tested quantitatively using a large sample.

In summary, the present study explores and summarizes an attribution model of community emergency volunteering during the COVID-19 pandemic, with the following significant innovations. (1) Most previous studies of the attribution of community volunteering were based on normal situations, but there is a lack of research on "community emergency volunteering" during emergency situations, such as during the COVID-19 pandemic, a conceptual category that cannot be equated with community volunteering in normal situations. Therefore, the basis of the present study is an exploration of volunteering and factors related to community volunteers in an abnormal emergency situation. (2) Existing studies in various countries are mostly presented in the form of quantitative statistics. However, there are relatively few exploratory qualitative studies on the application of grounded theory in this field. Therefore, it is not conducive to the intuitive analysis of factors and the exploration of related mechanisms but can be supplemented by innovative methods. (3) Looking at the existing research on the topic of emergency volunteer service, we find that China and the West have 


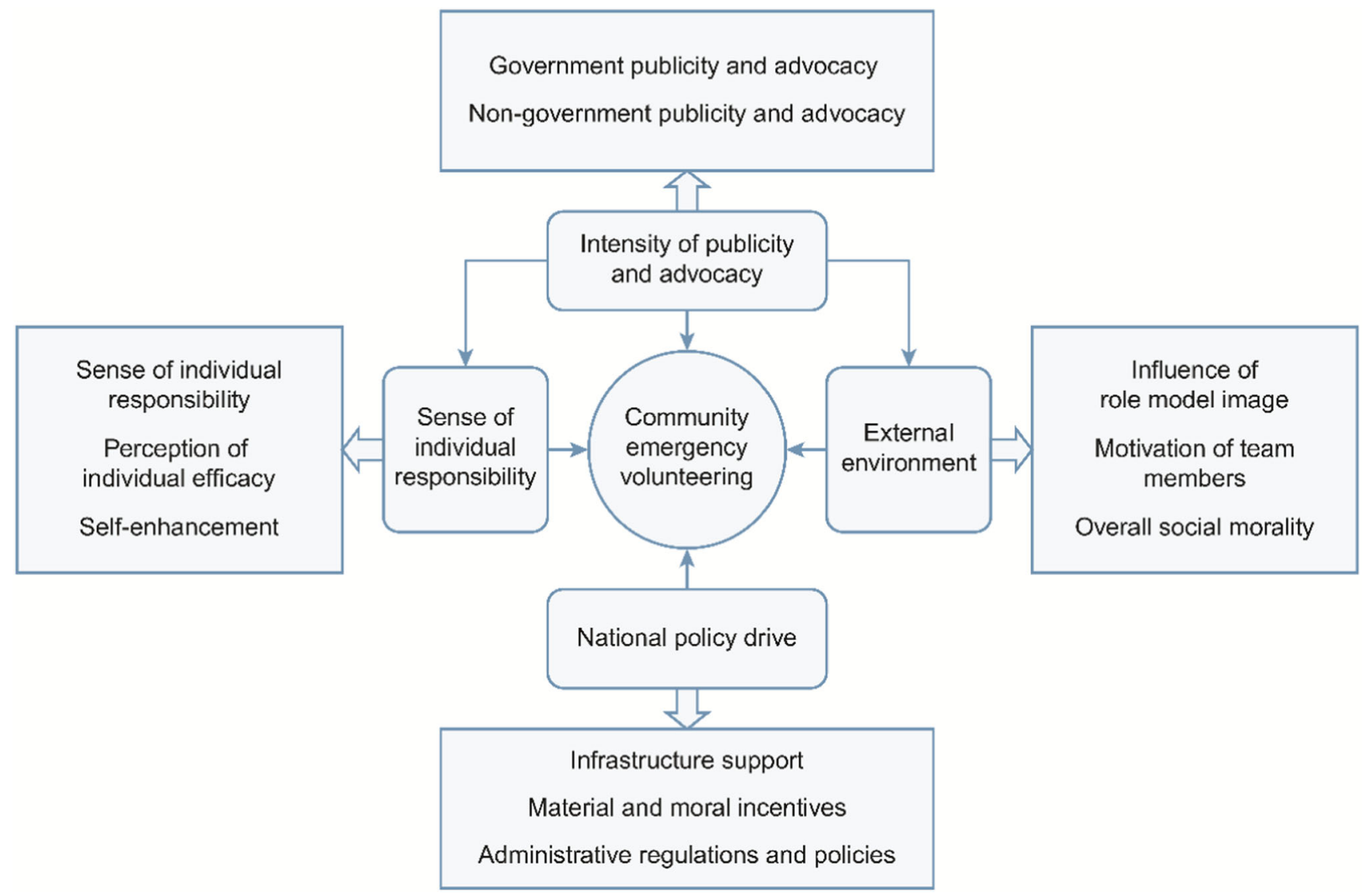

Fig. 1 Attribution model of community emergency volunteering during the COVID-19 pandemic

differences in politics, culture, and other aspects, and past research often ignores these differences. This study finds that the deep-seated driving force for the active cooperation and participation of some volunteers in China is their trust in the ruling party and the government as well as their overall recognition of pandemic prevention and control policies. This finding can also be used as a reference for studies in the context of other countries and thus serves as a contribution of this study.

Authors' Contribution LT designed the study, conducted interviews, analyzed the data, and wrote the manuscript; WWQ answered the questions and suggested amendments.

\section{Declaration}

Conflict of interest The author has no conflicts of interest to declare.

\section{References}

Aiken, L. (2008). Attitudes and related psychosocial constructs: Theories, assessment, and research. China Light Industry Press. Alzaghal, M., \& Momani, N. (2017). Emergency volunteering in Kingdom of Saudi Arabia: Current and future trends. International Journal of Emergency Management, 13, 160.
Aydinli, A., Bender, M., Chasiotis, A., Van de Vijver, F. J. R., Cemalcilar, Z., Chong, A., \& Yue, X. (2015). A cross-cultural study of explicit and implicit motivation for long-term volunteering. Nonprofit and Voluntary Sector Quarterly, 45, 375-396.

Batson, C. D., Ahmad, N., \& Tsang, J. A. (2002). Four motives for community involvement. Journal of Social Issues, 58, 429-445.

Bazan, D., Nowicki, M., \& Rzymski, P. (2021). Medical students as the volunteer workforce during the COVID-19 pandemic: Polish experience. International Journal of Disaster Risk Reduction, $55,102109$.

Beyerlein, K., \& Sikkink, D. (2008). Sorrow and solidarity: Why Americans volunteered for 9/11 relief efforts. Social Problems, $55,190-215$.

Billig, M. (2019). Incorporating volunteer youth in emergency teams: The effect of the cognitive-emotional spiral. Cogent Psychology, $6,1704610$.

Boyte, H. C. (2005). Reframing democracy: Governance, civic agency, and politics. Public Administration Review, 65, 536-546.

Bruyere, B., \& Rappe, S. (2007). Identifying the motivations of environmental volunteers. Journal of Environmental Planning and Management, 50, 503-516.

Caricati, L., Panari, C., \& Melleri, M. (2020). Group identification and self-efficacy associated with quality of life in emergency medical services volunteers: A cross-sectional investigation. Journal of Applied Social Psychology, 50, 476-488.

Chen, X. (2000). Qualitative research methods and social science research. Educational Science Publishing House.

Cheung, C. K., Lo, T. W., \& Liu, E. S. C. (2015). Sustaining social trust and volunteer role identity reciprocally over time in pre- 
adult, adult, and older volunteers. Journal of Social Service Research, 42, 70-83.

Cicognani, E., Pietrantoni, L., Palestini, L., \& Prati, G. (2009). Emergency workers' quality of life: The protective role of sense of community, efficacy beliefs and coping strategies. Social Indicators Research, 94, 449-463.

Cnaan, R. A., \& Cascio, T. A. (1999). Performance and commitment: Issues in management of volunteers in human service organizations. Journal of Social Service Research, 24, 1-37.

Collins-Jarvis, L. (1997). Participation and consensus in collective action organizations: The influence of interpersonal versus massmediated channels. Journal of Applied Communication Research, 25, 1-16.

Cowlishaw, S., Evans, L., \& McLennan, J. (2011). Balance between volunteer work and family roles: Testing a theoretical model of work-family conflict in the volunteer emergency services. Australian Journal of Psychology, 62, 169-178.

Dawson, C., Baker, P. L., \& Dowell, D. (2019). Getting into the 'Giving Habit': The dynamics of volunteering in the UK. VOLUNTAS: International Journal of Voluntary and Nonprofit Organizations, 30, 1006-1021.

Deschamps, J. C., \& Devos, T. (1998). Regarding the relationship between social identity and personal identity. Sage Publication.

Domaradzki, J., \& Walkowiak, D. (2021). Medical students' voluntary service during the COVID-19 pandemic in Poland. Frontiers in Public Health, 9, 618608.

Dury, S., Willems, J., De Witte, N., De Donder, L., Buffel, T., \& Verté, D. (2016). Municipality and neighborhood influences on volunteering in later life. Journal of Applied Gerontology, 35, $601-626$.

Edelenbos, J., Van Meerkerk, I., \& Schenk, T. (2016). The evolution of community self-organization in interaction with government institutions: Cross-case insights from three countries. The American Review of Public Administration, 48, 52-66.

Erentaite, R., Žukauskienė, R., Beyers, W., \& Pilkauskaite Valickiene, R. (2012). Is news media related to civic engagement? The effects of interest in and discussions about the news media on current and future civic engagement of adolescents. Journal of Adolescence, 35, 587-597.

Faulks, K. (2000). Citizenship. Sage.

Finkelstein, M., Penner, L., \& Brannick, M. (2005). Motive, role identity, and prosocial personality as predictors of volunteer activity. Social Behavior and Personality: An International Journal, 33, 403-418.

Finkelstien, M. A. (2009). Intrinsic vs. extrinsic motivational orientations and the volunteer process. Personality and Individual Differences, 46, 653-658.

Gibelman, M., \& Sweifach, J. (2008). Acting on our values: Do social workers volunteer? Social Work, 53, 53-64.

Handy, F., Cnaan, R. A., Hustinx, L., Kang, C., Brudney, J. L., HaskiLeventhal, D., Holmes, K., Meijs, L. C. P. M., Pessi, A. B., Ranade, B., Yamauchi, N., \& Zrinscak, S. (2009). A crosscultural examination of student volunteering: Is it all about résumé building? Nonprofit and Voluntary Sector Quarterly, 39, 498-523.

Harro-Loit, H., Vihalemm, T., \& Ugur, K. (2012). Cultural experience as a (critical) factor in crisis communication planning. Journal of Contingencies and Crisis Management, 20, 26-38.

$\mathrm{Hu}, \mathrm{M}$. (2020). Making the state's volunteers in contemporary China. VOLUNTAS: International Journal of Voluntary and Nonprofit Organizations. https://doi.org/10.1007/s11266-019-00190-9

Hustinx, L., Handy, F., Cnaan, R. A., Brudney, J. L., Pessi, A. B., \& Yamauchi, N. (2010). Social and cultural origins of motivations to volunteer: A comparison of university students in six countries. International Sociology, 25, 349-382.
Janoski, T., Musick, M., \& Wilson, J. (1998). Being volunteered? The impact of social participation and pro-social attitudes on volunteering. Sociological Forum, 13, 495-519.

Jasper, J. M. (1998). The emotions of protest: Affective and reactive emotions in and around social movements. Sociological Forum, 13, 397-424.

Kasdan, D. O. (2016). Considering socio-cultural factors of disaster risk management. Disaster Prevention and Management, 25, 464-477.

Kaun, A., \& Uldam, J. (2017). 'Volunteering is like any other business': Civic participation and social media. New Media \&amp; Society, 20, 2186-2207.

Kim, J. W., \& Jung, K. (2016). Does voluntary organizations' preparedness matter in enhancing emergency management of county governments? Lex Localis, 14, 1-17.

Kragt, D., Dunlop, P., Gagné, M., Holtrop, D., \& Luksyte, A. (2018). When joining is not enough: Emergency services volunteers and the intention to remain. Australian Journal of Emergency Management, 33, 35-40.

Kulik, L. (2016). Volunteering during an emergency: A life stage perspective. Nonprofit and Voluntary Sector Quarterly, 46, 419-441.

Liarakou, G., Kostelou, E., \& Gavrilakis, C. (2011). Environmental volunteers: Factors influencing their involvement in environmental action. Environmental Education Research, 17, 651-673.

Liu, F., \& Zhang, X. (2020). Who are volunteers in urban China? VOLUNTAS: International Journal of Voluntary and Nonprofit Organizations. https://doi.org/10.1007/s11266-020-00251-4

Luo, J., \& Wang, T. (2012). A study on the sustainability of volunteering behavior: Empirical data analysis based on college students' teaching volunteer program. Sociological Research, 94-118, 243-244.

Luova, O. (2011). Community volunteers' associations in contemporary Tianjin: Multipurpose partners of the party-state. Journal of Contemporary China, 20, 773-794.

Mainar, I. G., Servós, C. M., \& Gil, M. I. S. (2015). Analysis of volunteering among spanish children and young people: Approximation to their determinants and parental influence. VOLUNTAS: International Journal of Voluntary and Nonprofit Organizations, 26, 1360-1390.

Mayorga, M. E., Lodree, E. J., \& Wolczynski, J. (2017). The optimal assignment of spontaneous volunteers. Journal of the Operational Research Society, 68, 1106-1116.

Mekonen, Y. K., \& Adarkwah, M. A. (2021). Volunteers in the COVID-19 pandemic era: Intrinsic, extrinsic, or altruistic motivation? Postgraduate international students in China. Journal of Social Service Research. doi:https://doi.org/10.1080/ 01488376.2021 .1980482

Miao, J., Zeng, D., \& Shi, Z. (2020). Can neighborhoods protect residents from mental distress during the COVID-19 pandemic? Evidence from Wuhan. Chinese Sociological Review, 53, 1-26.

Miao, Q., Schwarz, S., \& Schwarz, G. (2021). Responding to COVID19: Community volunteerism and coproduction in China. World Development, 137, 105128.

Milbourn, B., Black, M. H., \& Buchanan, A. (2018). Why people leave community service organizations: A mixed methods study. VOLUNTAS: International Journal of Voluntary and Nonprofit Organizations, 30, 272-281.

Monllor, J., Pavez, I., \& Pareti, S. (2020). Understanding informal volunteer behavior for fast and resilient disaster recovery: An application of entrepreneurial effectuation theory. Disaster Prevention and Management: An International Journal, 29, 575-589.

Mowen, J. C., \& Sujan, H. (2005). Volunteer behavior: A hierarchical model approach for investigating its trait and functional motive antecedents. Journal of Consumer Psychology, 15, 170-182. 
Myers, D. (2006). Social psychology. Posts \& Telecom Press.

Nanavaty, J. (2020). Volunteerism during COVID-19. Public Health Nursing, 37, 797-798.

Nemoto, Y., Nonaka, K., Hasebe, M., Koike, T., Minami, U., Murayama, Y., Murayama, H., Matsunaga, H., Fukaya, T., \& Kobayashi, E. (2018). Factors that promote new or continuous participation in social group activity among Japanese community-dwelling older adults: A 2-year longitudinal study. Geriatrics \&amp; Gerontology International, 18, 1259-1266.

Nesbit, R. (2017). Advocacy recruits: Demographic predictors of volunteering for advocacy-related organizations. VOLUNTAS: International Journal of Voluntary and Nonprofit Organizations, 28, 958-987.

Ng, J., Zhao, S., \& Tan, Q. (2019). Spiral effect of volunteer service participation: Classical grounded theory research on the sustainability of college student volunteerism. Contemporary Youth Research, 33-39.

Oh, D. G. (2017). Analysis of the factors affecting volunteering, satisfaction, continuation will, and loyalty for public library volunteers: An integrated structural equation model. Journal of Librarianship and Information Science, 51, 894-914.

Ohmer, M. L. (2007). Citizen participation in neighborhood organizations and its relationship to volunteers' self- and collective efficacy and sense of community. Social Work Research, 31, $109-120$

Omoto, A. M., \& Snyder, M. (2002). Considerations of community: The context and process of volunteerism. American Behavioral Scientist, 45, 846-867.

Omoto, A. M., Snyder, M., \& Martino, S. C. (2000). Volunteerism and the life course: Investigating age-related agendas for action. Basic and Applied Social Psychology, 22, 181-197.

Penner, L. A. (2002). Dispositional and organizational influences on sustained volunteerism: An interactionist perspective. Journal of Social Issues, 58, 447-467.

Robinson, O. C. (2014). Sampling in interview-based qualitative research: A theoretical and practical guide. Qualitative Research in Psychology, 11, 25-41.

Rotolo, T., \& Berg, J. A. (2011). In times of need: An examination of emergency preparedness and disaster relief service volunteers. Nonprofit and Voluntary Sector Quarterly, 40, 740-750.

Saunders, B., Sim, J., Kingstone, T., Baker, S., Waterfield, J., Bartlam, B., Burroughs, H., \& Jinks, C. (2018). Saturation in qualitative research: Exploring its conceptualization and operationalization. Quality \&amp; Quantity, 52, 1893-1907.

Sheng, L., \& Weirong, R. (2020). "Family-bound" or "Pulled by work"?-A study of Chinese women's social participation and the factors influencing it. Social Sciences in China, 41, 133-158.

Shi, M., Xu, W., Gao, L., Kang, Z., Ning, N., Liu, C., Liang, C., Sun, H., Jiao, M., Liang, L., Li, Y., Cui, Y., Xiaowen, Z., Fei, J., Wei, Q., Yi, M., Hao, Y., \& Wu, Q. (2018). Emergency volunteering willingness and participation: A cross-sectional survey of residents in northern China. British Medical Journal Open, 8 , e020218.

Shi, P. (2012). On the role of government in integrated disaster risk governance-Based on practices in China. International Journal of Disaster Risk Science, 3, 139-146.

Southby, K., South, J., \& Bagnall, A. M. (2019). A rapid review of barriers to volunteering for potentially disadvantaged groups and implications for health inequalities. VOLUNTAS: International Journal of Voluntary and Nonprofit Organizations, 30, 907-920.

Spires, A. J. (2018). Chinese youth and alternative narratives of volunteering. China Information, 32, 203-223.

Strauss, A., \& Corbin, J. M. (1990). Basics of qualitative research: Grounded theory procedures and techniques. Sage.

Takase, Y., Hadi, A. A., \& Furuya, K. (2019). The relationship between volunteer motivations and variation in frequency of participation in conservation activities. Environmental Management, 63, 32-45.

Tempski, P., Arantes-Costa, F. M., Kobayasi, R., Siqueira, M. A. M., Torsani, M. B., Amaro, B., Nascimento, M., Siqueira, S. L., Santos, I. S., \& Martins, M. A. (2021). Medical students' perceptions and motivations during the COVID-19 pandemic. PLOS ONE, 16, e0248627.

Vanbeselcaere, N. (1994). Social identity theory: Constructive and critical advances. British Journal of Social Psychology, 33, 363-366.

Wang, L., Mook, L., \& Handy, F. (2016). An empirical examination of formal and informal volunteering in Canada. Voluntas:d International Journal of Voluntary and Nonprofit Organizations, 28, 139-161.

Whittaker, J., McLennan, B., \& Handmer, J. (2015). A review of informal volunteerism in emergencies and disasters: Definition, opportunities and challenges. International Journal of Disaster Risk Reduction, 13, 358-368.

Wilson, J. (2012). Volunteerism research: A review essay. Nonprofit and Voluntary Sector Quarterly, 41, 176-212.

Wu, Z., \& Bies, A. (2020). Volunteering and self-rated health in urban China: New evidence from analyses of treatment-effects models. Applied Research in Quality of Life, 16, 2185-2201.

Wu, Z., Zhao, R., Zhang, X., \& Liu, F. (2018). The impact of social capital on volunteering and giving: Evidence from urban China. Nonprofit and Voluntary Sector Quarterly, 47, 1201-1222.

Xie, L. (2017). Research on the current situation and influence factors of older people's participation in the community volunteer service in urban China. Market \&amp; Demographic Analysis, $23,55-65$.

Publisher's Note Springer Nature remains neutral with regard to jurisdictional claims in published maps and institutional affiliations. 